\title{
epicontacts: Handling, visualisation and analysis of
}

\section{epidemiological contacts [version 1; peer review: 1 approved,}

\section{1 approved with reservations]}

\author{
VP Nagraj(D1, Nistara Randhawa22, Finlay Campbell(iD)3, Thomas Crellen (iD), \\ Bertrand Sudre ${ }^{5}$, Thibaut Jombart (103 \\ ${ }^{1}$ Research Computing, University of Virginia School of Medicine, Charlottesville, VA, 22903, USA \\ 2One Health Institute, University of California, Davis, Davis, CA, 95616, USA \\ ${ }^{3}$ MRC Centre for Outbreak Analysis and Modelling, Department of Infectious Disease Epidemiology, School of Public Health, \\ Imperial College London, London, W2 1PG, UK \\ ${ }^{4}$ Mahidol-Oxford Tropical Medicine Research Unit, Bangkok, 10400, Thailand \\ ${ }^{5}$ European Centre for Disease Prevention and Control, Stockholm, Sweden
}

V1 First published: 10 May 2018, 7:566

https://doi.org/10.12688/f1000research.14492.1

Latest published: 11 Oct 2018, 7:566

https://doi.org/10.12688/f1000research.14492.2

\section{Abstract}

Epidemiological outbreak data is often captured in line list and contact format to facilitate contact tracing for outbreak control. epicontacts is an $\mathrm{R}$ package that provides a unique data structure for combining these data into a single object in order to facilitate more efficient visualisation and analysis. The package incorporates interactive visualisation functionality as well as network analysis techniques. Originally developed as part of the Hackout3 event, it is now developed, maintained and featured as part of the R Epidemics Consortium (RECON). The package is available for download from the Comprehensive R Archive Network (CRAN) and GitHub.

Keywords

contact tracing, outbreaks, R

This article is included in the RPackage gateway.

\section{Open Peer Review}

Approval Status ?

12

23

version 2

(revision)

11 Oct 2018

version 1

10 May 2018

$\begin{array}{cc}? & \checkmark \\ \text { view } & \text { view }\end{array}$

1. Melissa A. Rolfes, Centers for Disease

Control and Prevention (CDC), Atlanta, USA

2. Peter Adebayo Adewuyi, Liberia Field

Epidemiology Training Program, Monrovia,

Liberia

African Field Epidemiology Network (AFENET),

Kampala, Uganda

3. Josie Athens (iD), University of Otago,

Dunedin, New Zealand

Any reports and responses or comments on the article can be found at the end of the article. 


\section{Corresponding author: VP Nagraj (vpnagraj@virginia.edu)}

Author roles: Nagraj V: Conceptualization, Software, Writing - Original Draft Preparation; Randhawa N: Conceptualization, Software, Writing - Original Draft Preparation; Campbell F: Conceptualization, Software, Writing - Original Draft Preparation; Crellen T:

Conceptualization, Software; Sudre B: Conceptualization; Jombart T: Conceptualization, Software, Writing - Original Draft Preparation

Competing interests: No competing interests were disclosed.

Grant information: The author(s) declared that no grants were involved in supporting this work.

Copyright: @ 2018 Nagraj $\vee$ et al. This is an open access article distributed under the terms of the Creative Commons Attribution License , which permits unrestricted use, distribution, and reproduction in any medium, provided the original work is properly cited.

How to cite this article: Nagraj V, Randhawa N, Campbell F et al. epicontacts: Handling, visualisation and analysis of epidemiological contacts [version 1; peer review: 1 approved, 1 approved with reservations] F1000Research 2018, 7:566

https://doi.org/10.12688/f1000research.14492.1

First published: 10 May 2018, 7:566 https://doi.org/10.12688/f1000research.14492.1 


\section{Introduction}

In order to study, prepare for, and intervene against disease outbreaks, infectious disease modellers and public health professionals need an extensive data analysis toolbox. Disease outbreak analytics involve a wide range of tasks that need to be linked together, from data collection and curation to exploratory analyses, and more advanced modelling techniques used for incidence forecasting ${ }^{1,2}$ or to predict the impact of specific interventions ${ }^{3,4}$. Recent outbreak responses suggest that for such analyses to be as informative as possible, they need to rely on a wealth of available data, including timing of symptoms, characterisation of key delay distributions (e.g. incubation period, serial interval), and data on contacts between patients ${ }^{5-8}$.

The latter type of data is particularly important for outbreak analysis, not only because contacts between patients are useful for unravelling the drivers of an epidemic ${ }^{9,10}$, but also because identifying new cases early can reduce ongoing transmission via contact tracing, i.e. follow-up of individuals who reported contacts with known cases ${ }^{11,12}$. However, curating contact data and linking them to existing line lists of cases is often challenging, and tools for storing, handling, and visualising contact data are often missing ${ }^{13,14}$.

Here, we introduce epicontacts, an $\mathrm{R}^{15}$ package providing a suite of tools aimed at merging line lists and contact data, and providing basic functionality for handling, visualising and analysing epidemiological contact data. Maintained as part of the R Epidemics Consortium (RECON), the package is integrated into an ecosystem of tools for outbreak response using the $\mathrm{R}$ language.

\section{Methods}

Operation

epicontacts is released as an open-source R package. A stable release is available for Windows, Mac and Linux operating systems via the CRAN repository. The latest development version of the package is available through the RECON Github organization. At minimum users must have $\mathrm{R}$ installed. No other system dependencies are required.

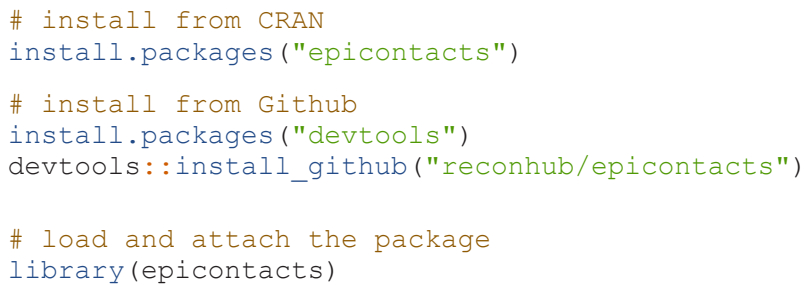

\section{Implementation}

Data handling. epicontacts includes a novel data structure to accommodate line list and contact list datasets in a single object. This object is constructed with the make epiconctacts () function and includes attributes from the original datasets. Once combined, these are mapped internally in a graph paradigm as nodes and edges. The epicontacts data structure also includes a logical attribute for whether or not this resulting network is directed.

The package takes advantage of R's generic functions, which call specific methods depending on the class of an object. This is implemented in several places, including the summary.epicontacts () and print.epicontacts () methods, both of which are respectively called when the summary() or print() functions are used on an epicontacts object. The package does not include built-in data, as exemplary contact and line list datasets are available in the outbreaks package ${ }^{16}$.

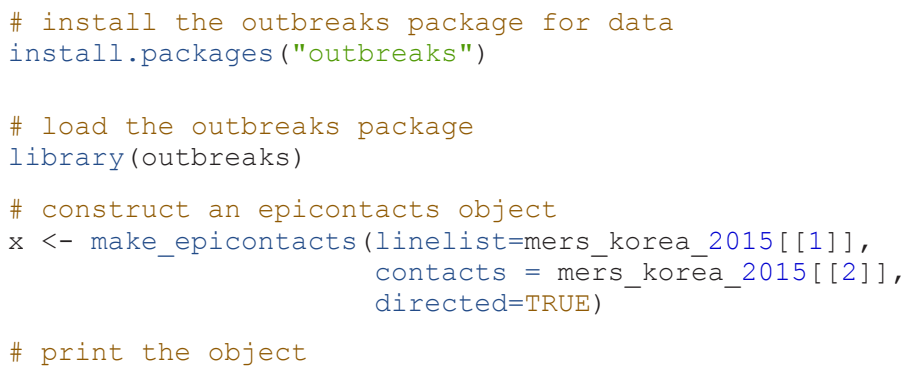




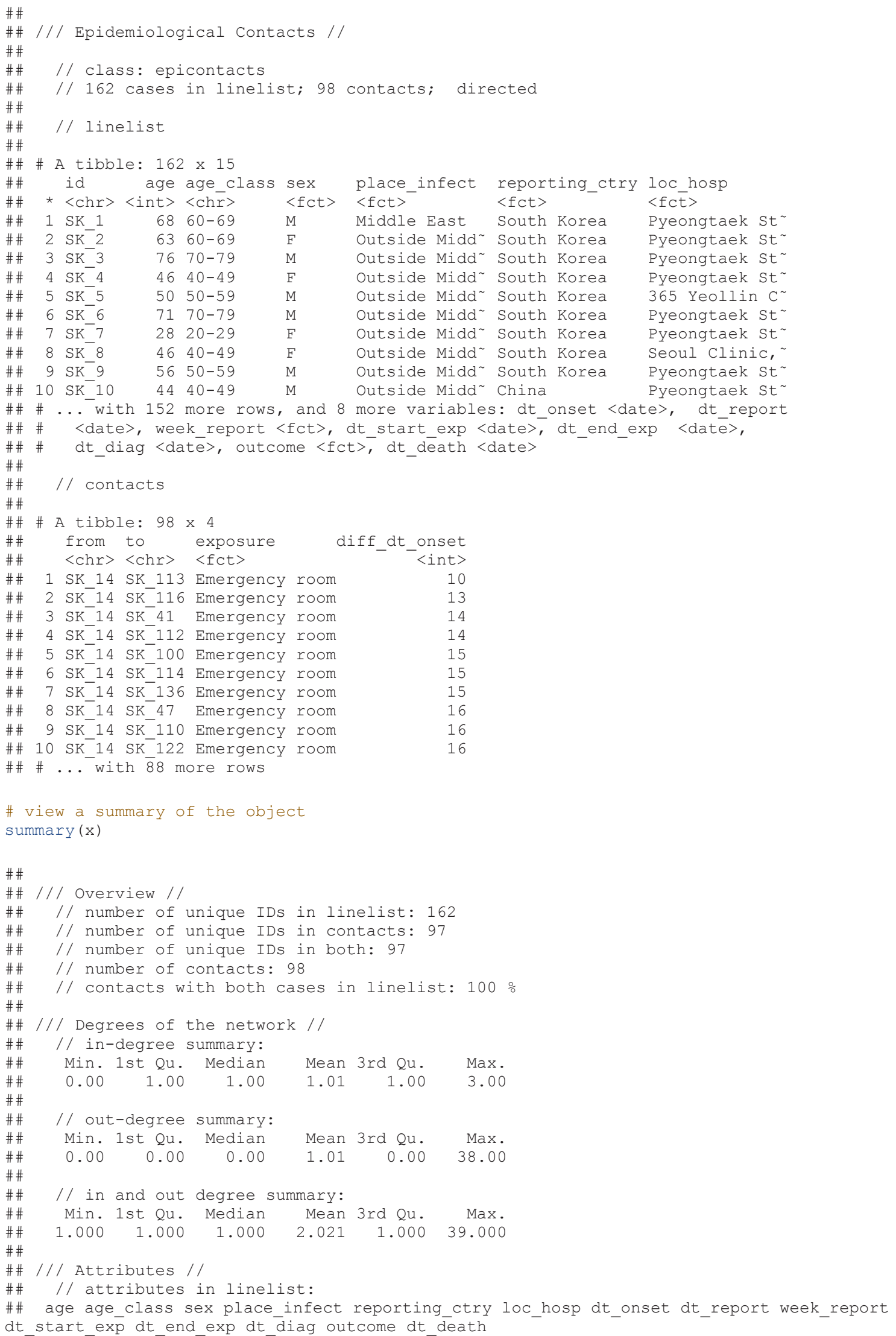




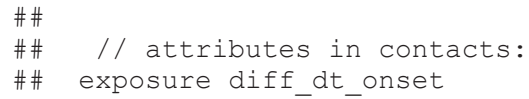

Data visualisation. epicontacts implements two interactive network visualisation packages: visNetwork and threej $\mathrm{s}^{17,18}$. These frameworks provide R interfaces to the vis.js and three.js JavaScript libraries respectively. Their functionality is incorporated in the generic plot () method (Figure 1) for an epicontacts object, which can be toggled between either with the "type" parameter. Alternatively, the visNetwork interactivity is accessible viavis epicontacts () (Figure 2), and threejs through graph3D () (Figure 3). Each function has a series of arguments that can also be passed through plot ( ). Both share a color palette, and users can specify node, edge and background colors. However, vis_epicontacts () includes a specification for "node_ shape" by a line list attribute as well as a customization of that shape with an icon from the Font Awesome icon library. The principal distinction between the two is that $g r a p h 3 D()$ is a three-dimensional visualisation, allowing users to rotate clusters of nodes to better inspect their relationships.
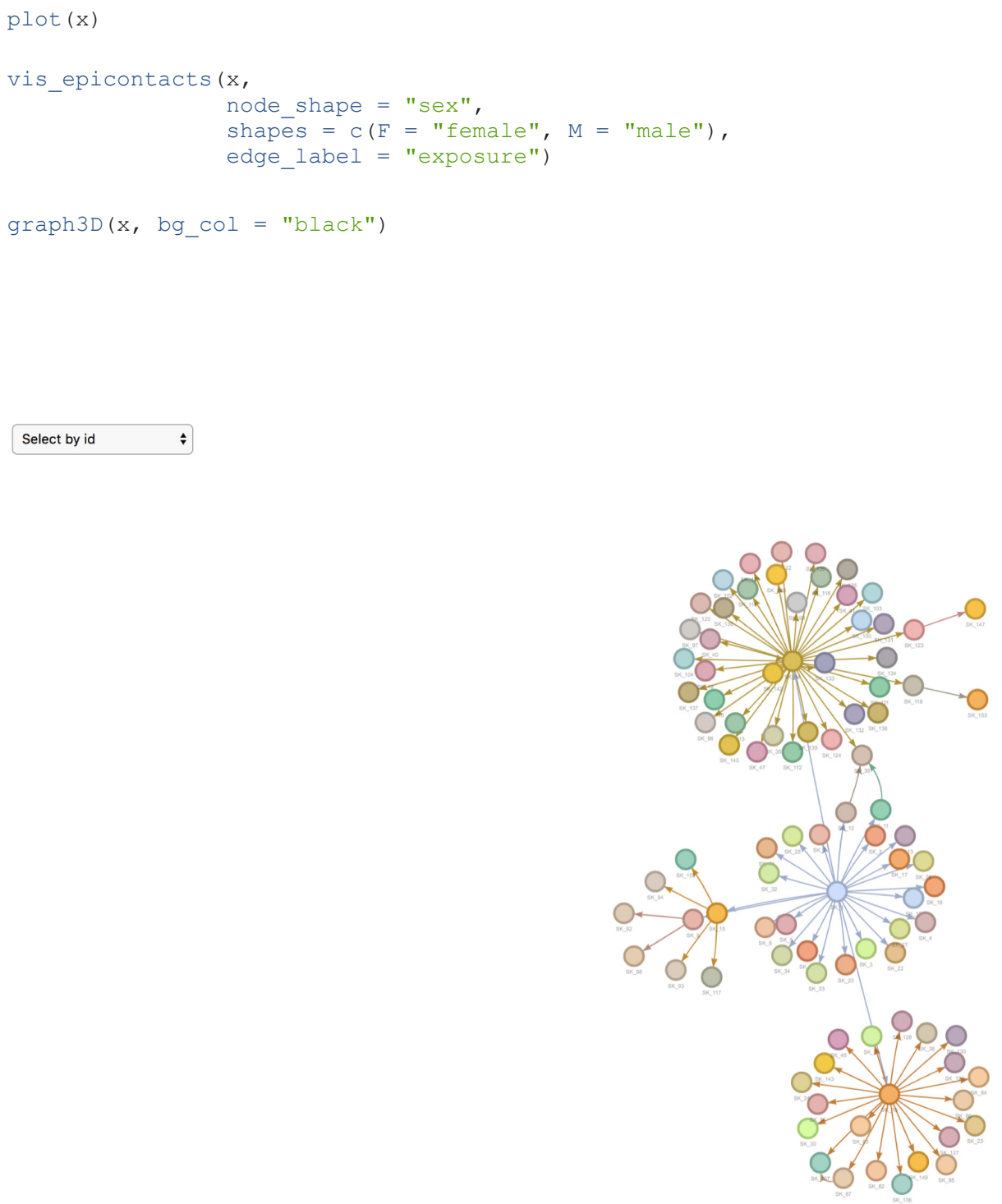

Figure 1. The generic plot() method for an epicontacts object will use the visNetwork method by default. 


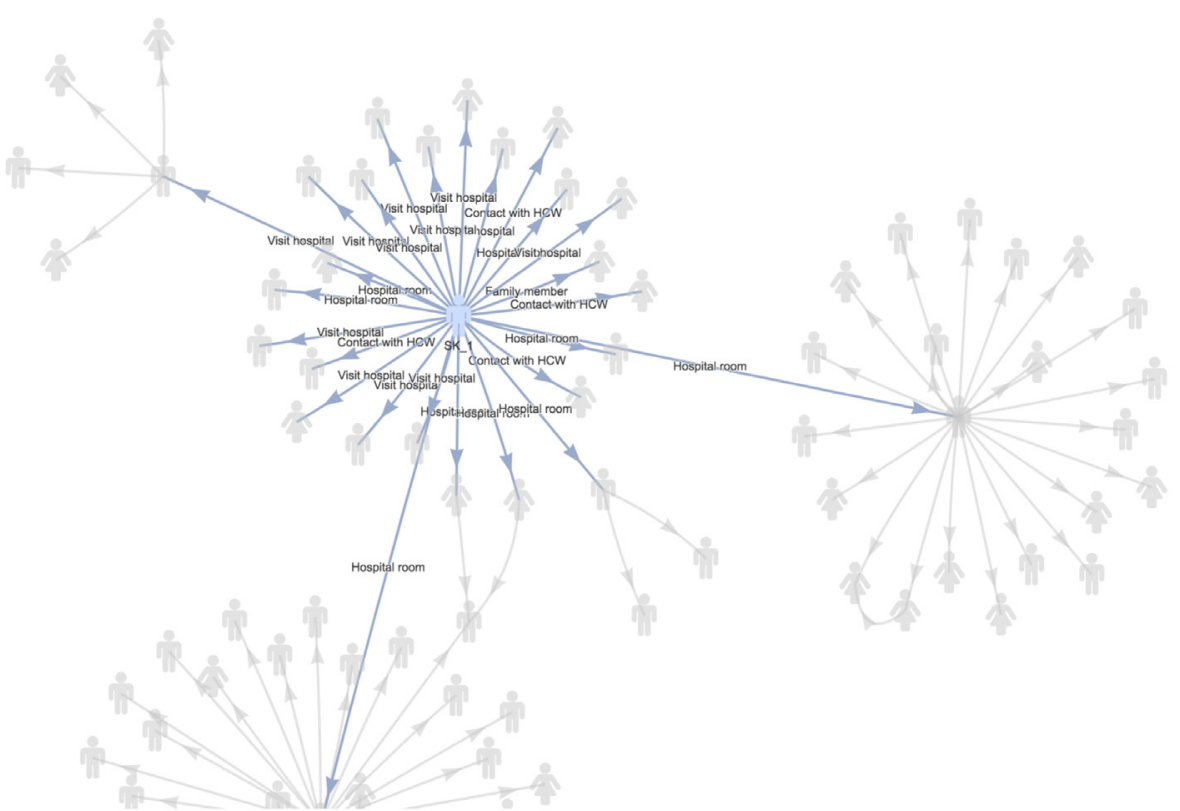

Figure 2. The vis_epicontacts() function explicitly calls visNetwork to make an interactive plot of the contact network.

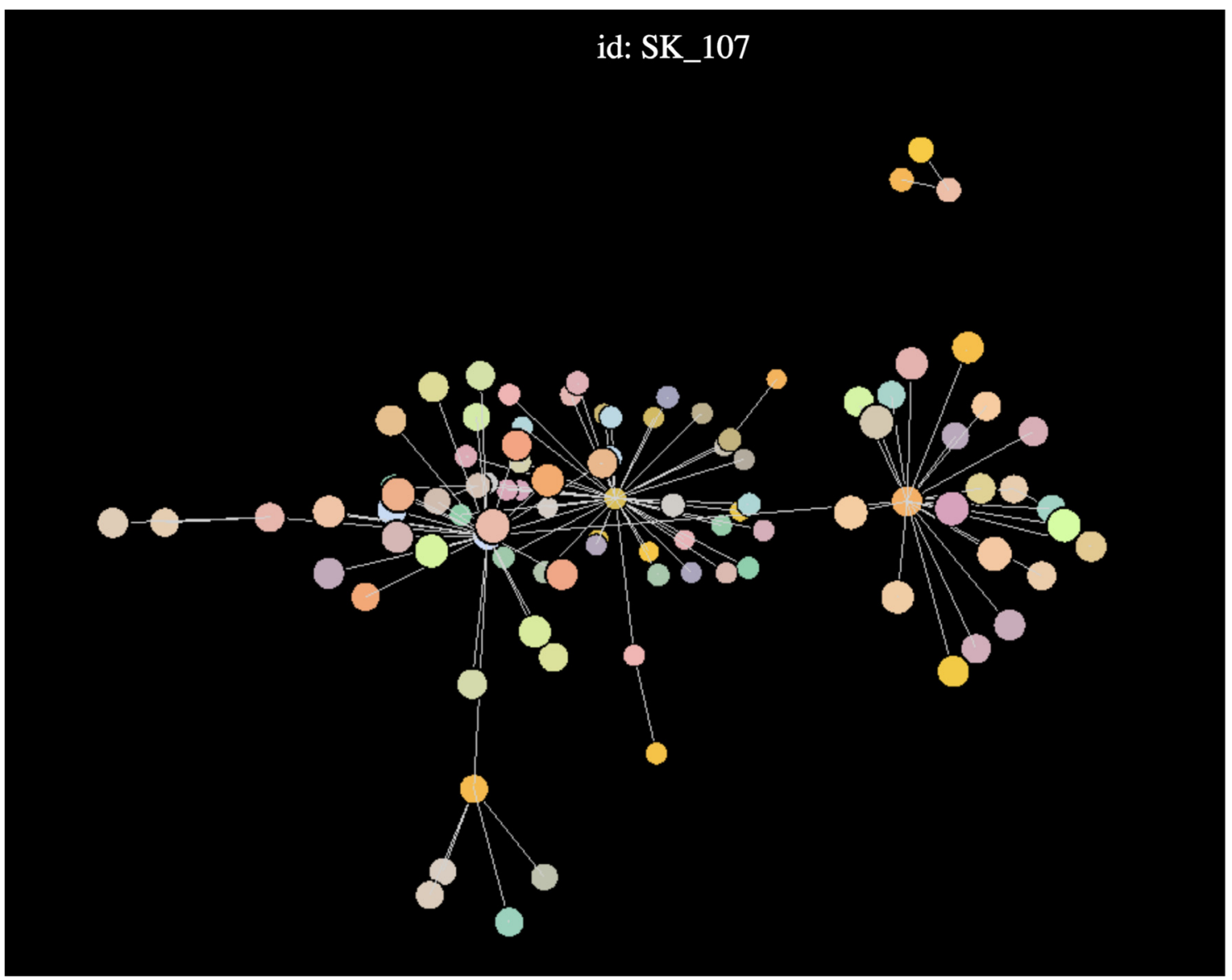

Figure 3. The graph3D() function generates a three-dimensional network plot. 
Data analysis. Subsetting is a typical preliminary step in data analysis. epi contacts leverages a customized subset method to filter line list or contacts based on values of particular attributes from nodes, edges or both. If users are interested in returning only contacts that appear in the line list (or vice versa), the thin () function implements such logic.

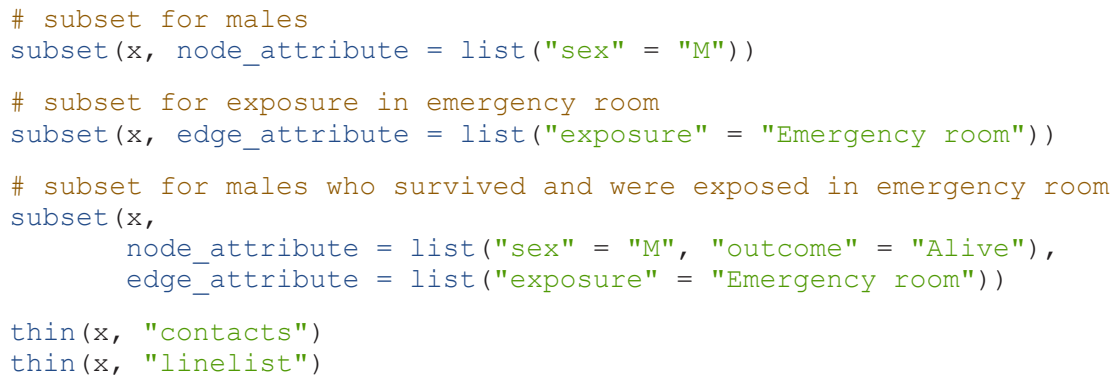

For analysis of pairwise contact between individuals, the get pairwise() feature searches the line list based on the specified attribute. If the given column is a numeric or date object, the function will return a vector containing the difference of the values of the corresponding "from" and "to" contacts. This can be particularly useful, for example, if the line list includes the date of onset of each case. The subtracted value of the contacts would approximate the serial interval for the outbreak ${ }^{19}$. For factors, character vectors and other non-numeric attributes, the default behavior is to print the associated line list attribute for each pair of contacts. The function includes a further parameter to pass an arbitrary function to process the specified attributes. In the case of a character vector, this can be helpful for tabulating information about different contact pairings with table () .

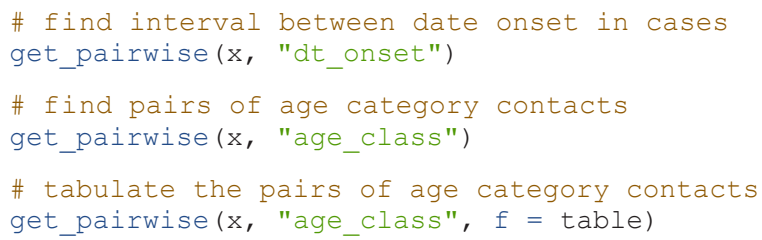

\section{Use cases}

Those interested in using epicontacts should have a line list of cases as well as a record of contacts between individuals. Both datasets must be enumerated in tabular format with rows and columns. At minimum the line list requires one column with a unique identifier for every case. The contact list needs two columns for the source and destination of each pair of contacts. The datasets can include arbitrary features of case or contact beyond these columns. Once loaded into R and stored as data. frame objects, these datasets can be passed to the make epicontacts () function (see 'Methods' section for more detail). For an example of data prepared in this format, users can refer to the outbreaks R package.

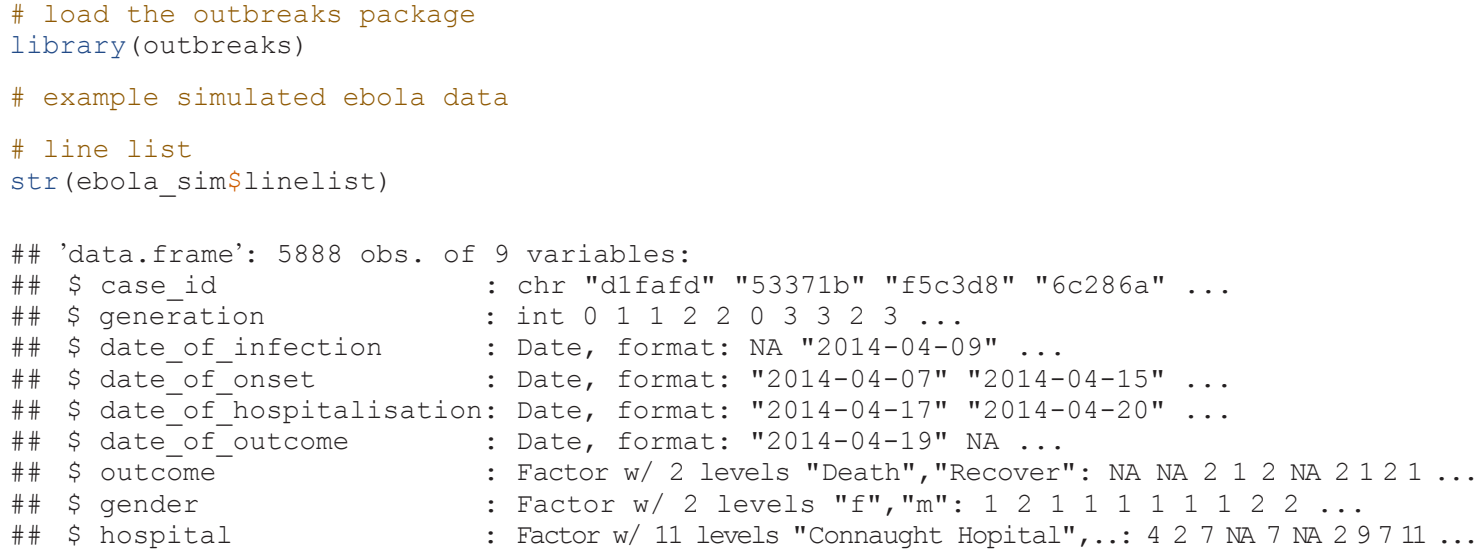




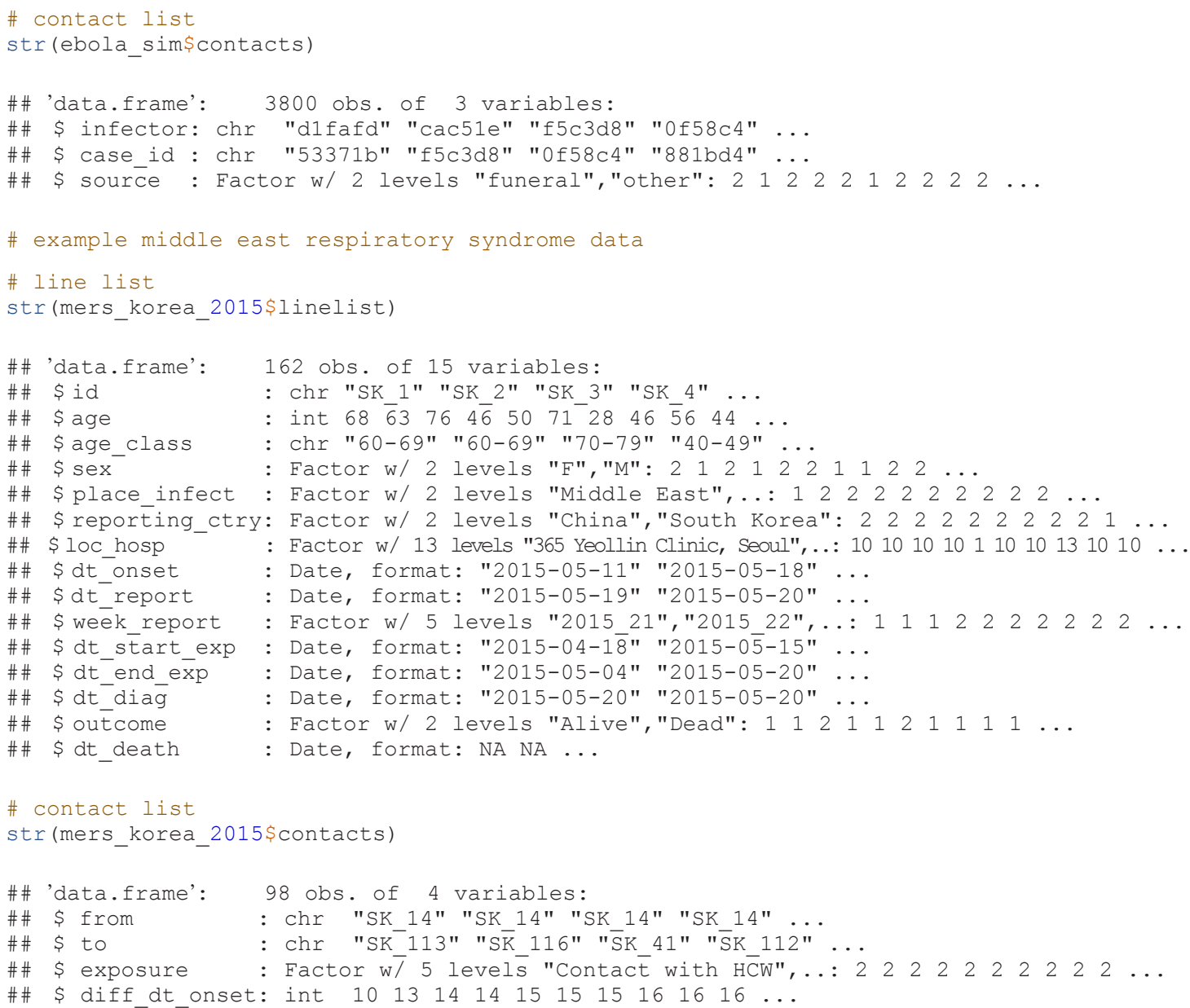

\section{Discussion}

\section{Benefits}

While there are software packages available for epidemiological contact visualisation and analysis, none aim to accommodate line list and contact data as purposively as epicontact ${ }^{20-22}$. Furthermore, this package strives to solve a problem of plotting dense graphs by implementing interactive network visualisation tools. A static plot of a network with many nodes and edges may be difficult to interpret. However, by rotating or hovering over an epicontacts visualisation, a user may better understand the data.

Future considerations

The maintainers of epicontacts anticipate new features and functionality. Future development could involve performance optimization for visualising large networks, as generating these interactive plots is resource intensive. Additionally, attention may be directed towards inclusion of alternative visualisation methods.

\section{Conclusions}

epicontacts provides a unified interface for processing, visualising and analyzing disease outbreak data in the R language. The package and its source are freely available on CRAN and GitHub. By developing functionality with line list and contact list data in mind, the authors aim to enable more efficient epidemiological outbreak analyses.

\section{Software availability}

Software available from: https://CRAN.R-project.org/package=epicontacts

Source code available from: https://github.com/reconhub/epicontacts

Archived source code as at time of publication: https://zenodo.org/record/121099323

Software license: GPL 2 
Competing interests

No competing interests were disclosed.

Grant information

The author(s) declared that no grants were involved in supporting this work.

\section{Acknowledgements}

The authors would like to thank all of the organizers and participants of the Hackout3 event held in Berkeley, California June 20-24, 2016. In particular, the authors acknowledge the support of the following organizations: MRC Centre for Outbreak Analysis, and Modelling at Imperial College London, the NIHR's Modelling Methodology Health Protection Research Unit at Imperial College London, and the Berkeley Institute for Data Science.

1. Funk S, Camacho A, Kucharski AJ, et al.: Real-time forecasting of infectious disease dynamics with a stochastic semi-mechanistic model. Epidemics. 2018; 22: 56-61.

PubMed Abstract | Publisher Full Text | Free Full Text

2. Nouvellet $P$, Cori A, Garske $T$, et al.: A simple approach to measure transmissibility and forecast incidence. Epidemics. 2018; 22: 29-35.

PubMed Abstract | Publisher Full Text | Free Full Text

3. Nouvellet $\mathrm{P}$, Garske T, Mills HL, et al.: The role of rapid diagnostics in managing Ebola epidemics. Nature. 2015; 528(7580): S109-116.

PubMed Abstract | Publisher Full Text | Free Full Text

4. Parker EP, Molodecky NA, Pons-Salort M, et al:: Impact of inactivated poliovirus vaccine on mucosal immunity: implications for the polio eradication endgame. Expert Rev Vaccines. 2015; 14(8): 1113-1123.

PubMed Abstract | Publisher Full Text | Free Full Text

5. Cauchemez S, Fraser C, Van Kerkhove MD, et al:: Middle East respiratory syndrome coronavirus: quantification of the extent of the epidemic, surveillance biases, and transmissibility. Lancet Infect Dis. 2014; 14(1): 50-56.

PubMed Abstract | Publisher Full Text | Free Full Text

6. WHO Ebola Response Team, Aylward B, Barboza P, et al.: Ebola virus disease in West Africa--the first 9 months of the epidemic and forward projections. N Engl J Med. 2014; 371(16): 1481-1495. PubMed Abstract | Publisher Full Text | Free Full Tex

7. WHO Ebola Response Team, Agua-Agum J, Ariyarajah A, et al: West African Ebola epidemic after one year--slowing but not yet under control. N Engl J Med. 2015; 372(6): 584-587. PubMed Abstract | Publisher Full Text | Free Full Text

8. Cori A, Donnelly CA, Dorigatti I, et al:: Key data for outbreak evaluation: building on the Ebola experience. Philos Trans $R$ Soc Lond B Biol Sci. 2017; 372(1721).

PubMed Abstract | Publisher Full Text | Free Full Text

9. International Ebola Response Team, Agua-Agum J, Ariyarajah A, et al:: Exposure Patterns Driving Ebola Transmission in West Africa: A Retrospective Observational Study. PLoS Med. 2016; 13(11): e1002170.

PubMed Abstract | Publisher Full Text | Free Full Text

10. Cauchemez $S$, Nouvellet $P$, Cori $A$, et al.: Unraveling the drivers of MERS-CoV transmission. Proc Natl Acad Sci U S A. 2016; 113(32): 9081-9086.

PubMed Abstract | Publisher Full Text | Free Full Text

11. Senga $M$, Koi $A$, Moses $L$, et al.: Contact tracing performance during the Ebola virus disease outbreak in Kenema district,
Sierra Leone. Philos Trans R Soc Lond B Biol Sci. 2017; 372(1721). PubMed Abstract | Publisher Full Text | Free Full Text

12. Saurabh S, Prateek S: Role of contact tracing in containing the 2014 Ebola outbreak: a review. Afr Health Sci. 2017; 17(1): 225-236.

PubMed Abstract | Publisher Full Text | Free Full Text

13. World Health Organization: Response to Measles Outbreaks in Measles Mortality Reduction Settings: Immunization, Vaccines and Biologicals. 2009 PubMed Abstract

14. Rakesh $\mathrm{P}$, Sherin $\mathrm{D}$, Sankar $\mathrm{H}$, et al:: Investigating a community wide outbreak of hepatitis a in India. J Glob Infect Dis. 2014; 6(2): 59-64.

PubMed Abstract | Publisher Full Text | Free Full Text

15. R Core Team: R: A Language and Environment for Statistical Computing. R Foundation for Statistical Computing, Vienna, Austria. 2017.

Reference Source

16. Jombart T, Frost S, Nouvellet P, et al.: outbreaks: A Collection of Disease Outbreak Data. R package version 1.3.0. 2017. Reference Source

17. Almende BV, Thieurmel B, Robert T: visNetwork: Network Visualization using 'vis.js' Library. R package version 2.0.3. 2018. Reference Source

18. Lewis BW: threejs: Interactive 3D Scatter Plots, Networks and Globes. R package version 0.3.1. 2017 Reference Source

19. Fine PE: The interval between successive cases of an infectious disease. Am J Epidemiol. 2003; 158(11): 1039-1047. PubMed Abstract | Publisher Full Text

20. Nöremark M, Widgren S: EpiContactTrace: an R-package for contact tracing during livestock disease outbreaks and for riskbased surveillance. BMC Vet Res. 2014; 10: 71 PubMed Abstract | Publisher Full Text | Free Full Text

21. Carroll LN, Au AP, Detwiler LT, et al.: Visualization and analytics tools for infectious disease epidemiology: a systematic review. J Biomed Inform. 2014; 51: 287-298. PubMed Abstract | Publisher Full Text | Free Full Text

22. Guthrie JL, Alexander DC, Marchand-Austin A, et al:: Technology and tuberculosis control: the OUT-TB Web experience. $J$ Am Med Inform Assoc. 2017; 24(e1): e136-e142. PubMed Abstract | Publisher Full Text

23. Nagraj VP, Jombart T, Randhawa N, et al.: epicontacts (Version 1.1.1). Zenodo. 2018 Data Source 


\section{Open Peer Review}

\section{Current Peer Review Status:}

\section{Version 1}

Reviewer Report 02 August 2018

https://doi.org/10.5256/f1000research.15777.r36044

(C) 2018 Adewuyi P. This is an open access peer review report distributed under the terms of the Creative Commons Attribution License, which permits unrestricted use, distribution, and reproduction in any medium, provided the original work is properly cited.

\section{Peter Adebayo Adewuyi}

${ }^{1}$ Liberia Field Epidemiology Training Program, Monrovia, Liberia

2 African Field Epidemiology Network (AFENET), Kampala, Uganda

This is a good software developed which could help in continuous visualization of contacts and their progression in disease tracking.

It is user friendly for those who are not computer specialist and still want to visualize data.

Data visualization is pertinent to disease monitoring and what the authors have done will aid in helping epidemiologist and public health specialist involved in outbreak response to quickly visualize progression and spread of disease from primary to secondary contacts and how the disease is evolving among contacts.

The software will actually achieve its purpose as stated in the conclusion of the write-up. Good work done.

Is the rationale for developing the new software tool clearly explained?

Yes

Is the description of the software tool technically sound?

Yes

Are sufficient details of the code, methods and analysis (if applicable) provided to allow replication of the software development and its use by others?

Yes

Is sufficient information provided to allow interpretation of the expected output datasets and any results generated using the tool? 


\section{Are the conclusions about the tool and its performance adequately supported by the findings presented in the article? \\ Yes}

Competing Interests: No competing interests were disclosed.

\section{I confirm that I have read this submission and believe that I have an appropriate level of expertise to confirm that it is of an acceptable scientific standard.}

Reviewer Report 31 May 2018

https://doi.org/10.5256/f1000research.15777.r34084

(C) 2018 Rolfes M. This is an open access peer review report distributed under the terms of the Creative Commons Attribution License, which permits unrestricted use, distribution, and reproduction in any medium, provided the original work is properly cited.

\section{Melissa A. Rolfes}

Centers for Disease Control and Prevention (CDC) , Atlanta, GA, USA

The article describes an R-based software tool aimed to facilitate analysis of data from outbreaks that include line lists of cases and case-contact data. The R package, epicontacts, is part of a larger suite of tools housed at the R Epidemics Consortium (RECON). The epicontacts package has the ability to merge data about cases in a line list with case-contact details, which then allows the user to describe and visualize contact networks, incubation periods, and serial intervals within an outbreak.

The codes and methods for analysis are partly described in the article, and the authors should provide a link to the packages documentation, either at CRAN or RECON webpages, where readers could learn more about the package and its options.

The output of the package provided in the article was interesting and intriguing. I felt that it was only partly explained and the article could benefit from the authors annotating the output and its interpretation a bit further. I have explored the RECON website and found the RECON Learn modules to be quite helpful in providing annotation of the epicontacts output and some guidance on interpretation. I would recommend that the authors consider either expanding the annotation of the output in this article or explicitly direct readers to the RECON Learn website for further instruction.

Additional suggestions:

Consider moving the section of the article called "Use cases" to before the "Data handling" subsection of the "Implementation" section. I felt that the description of the input datasets under "Use cases" was very informative and would have been organizational more helpful had it been placed earlier in the article.

Consider describing the sample outbreak data in a bit further detail. It appears to be data 
describing the MERS outbreak that occurred in South Korea in 2015. I think the description should include whether the data are simulated or from a real outbreak (if from a real outbreak, then a reference to the outbreak description should be included), the scenario of the outbreak, how many cases, how many contacts, place of the outbreak, duration of the outbreak, and a brief description of the demographic details included in the dataset. This amount of detail would allow the reader to translate the details of the outbreak from your text to the output provided by epicontacts.

Is the rationale for developing the new software tool clearly explained?

Yes

Is the description of the software tool technically sound?

Yes

Are sufficient details of the code, methods and analysis (if applicable) provided to allow replication of the software development and its use by others?

Partly

Is sufficient information provided to allow interpretation of the expected output datasets and any results generated using the tool?

Partly

Are the conclusions about the tool and its performance adequately supported by the findings presented in the article?

Yes

Competing Interests: No competing interests were disclosed.

I confirm that I have read this submission and believe that I have an appropriate level of expertise to confirm that it is of an acceptable scientific standard, however I have significant reservations, as outlined above. 
The benefits of publishing with F1000Research:

- Your article is published within days, with no editorial bias

- You can publish traditional articles, null/negative results, case reports, data notes and more

- The peer review process is transparent and collaborative

- Your article is indexed in PubMed after passing peer review

- Dedicated customer support at every stage

For pre-submission enquiries, contact research@f1000.com 